\title{
Roles And Responsibilities In Team Projects
}

Timothy C. Johnston (E-mail: johnston@utm.edu), University of Tennessee at Martin

\begin{abstract}
What roles assure that a student learns from a team project? This paper discusses student roles of (1) ready learner, (2) coachee, (3) contributor, (4) team member, and (5) academic scholar. Students can gain real world experience from a team project with a practitioner "client." But team projects can be flawed with ambiguous activities and free-riding students. A shift from the role of passive student to the active roles discussed in this paper can improve the team project learning experience. This paper also presents a model that apportions responsibilities to the teacher, students, and clients for team project tasks. Clear responsibilities can prepare students for their active roles in a team project. A well-defined project process can minimize the ambiguity inherent in real-world projects, and help the teacher maintain his or her course workload at a manageable level. The project steps are (1) set learning goals, (2) engage a client, (3) set project objectives, (4) implementation, (5) report results, and (6) assess performance.
\end{abstract}

\section{INTRODUCTION}

$\mathscr{R}$ eal world projects are an active learning approach in which teams of students pursue real world objectives as part of an academic course of study. Students take the major role in team class projects, working alongside the teacher, and sometimes a client. Projects are designed to give students some real world experience. Yet students are not paid and are not employed in an ongoing relationship with the client organization. The primary objective of a team project is to support academic learning, not to accomplish client objectives. What are the roles of a student in assuring that he or she learns from participating in the project? This paper discusses five student roles that are especially relevant to learning with team projects.

Also, how do the responsibilities of student, teacher and client change as the teaching model shifts from passive and teacher-centered to a team project that features active, student-centered learning? Clear responsibilities can help prepare students for their active roles in a team project. A well-defined project process can minimize the ambiguity inherent in real-world projects, and help the teacher maintain his or her course workload at a manageable level. This paper addresses this question by discussing the responsibilities of student, teacher, and client in the project process.

\section{Student Roles}

What follows is a discussion of the student roles in team learning of (1) ready learner, (2) coachee, (3) contributor, (4) team member, and (5) academic scholar, shown in Table 1.

Table 1: Student roles in team learning

\begin{tabular}{|l|l|}
\hline Student role: & Definition: \\
\hline Ready learner & Hold realistic expectations; is qualified \\
\hline Coachee & Apply concepts; seek help when needed \\
\hline Contributor & Contribute to classmates' learning experience \\
\hline Team member & Participate in and learn teamwork \\
\hline Academic scholar & Learn the course content \\
\hline
\end{tabular}




\section{Student as Ready Learner}

A student is ready to learn in a real world project format if he or she (1) is qualified to participate in a team project, and (2) has realistic expectations about the process. Students are not fully formed people, much less fully functioning managers. One cannot expect students to be qualified to complete a project. But some students are more qualified, or ready to participate in project learning, than others. Students should be relatively mature, use good judgment, be willing to negotiate, and be willing to "go the extra mile" to get the job done (Papamarcos, 2002). Students should also have a desire to gain experience or to serve a client as sufficient reward for their extra effort.

Students should bring some technical, interpersonal, communication and creative thinking skills to the project. They should be willing to subordinate their personal preferences to the decisions of the team, and be willing to compromise in order to achieve a group consensus. Students should be trustworthy in terms of their ability to represent the university to their client, and to keep client information confidential as needed.

As a teacher, one might not have the power to accept or deny enrollment in a course based on student qualifications to undertake a project. However, a teacher may communicate the qualifications so that students who feel unqualified or strongly averse to pursing a project may self-select out of the course, and choose to enroll after they acquire skills or to take another course option. A teacher can use pre-qualification data to form balanced teams, with less-qualified students joined with more-qualified students.

Students also need to begin a project with realistic expectations about the process. Students must replace their "traditional" course expectations with an awareness of the characteristics of a project. Real world problems that are inherently ambiguous have no obvious action plan and no right or wrong answer. Many traditional college students have "ambiguity aversion." They are used to passive classroom teaching methods in which the process and outcomes of learning are fairly clear in advance. Indeed, the opportunity to learn about the ambiguity of real world projects, and how to deal with it, is a benefit to students of doing projects.

The author has found that student satisfaction ratings of courses that feature real world projects are a bimodal distribution. Many students have rated a course with real world projects highly, while many any other students rated it very low: "You either love it or you hate it." Dissatisfied students cite a number of factors, including bad experiences with their team, a bad client, and unhappiness with the project process.

A teacher can reduce post-project student dissatisfaction by managing pre-project expectations. The teacher should clearly describe his or her teaching philosophy regarding groups early in the course (preferably before the adddrop deadline). Crustinger, et al (2004) describe the "transference" technique, which transfers "responsibility for work and performance from the faculty member to the student." Transference claims that a teacher "can instill in students self-motivating attitudes and behaviors and help them develop a strong sense of ownership of their academic pursuits."

Each student should know in advance that his or her initiative will determine the success of the project, that one's performance (and grade) is linked with one's teammates, that the project process will be ambiguous, that the project outcome has no right or wrong answer, and that the project will involve a client who is a potential "wild card" in the process. Despite the warning, some students will not thrive in a real world project environment and will give the course a low rating. Students find it difficult to have realistic expectations about something that they have never experienced, such as a real world project. Another reason for low ratings is that students knew what to expect, and didn't like it, but took the course because it was their only option to earn credit.

In summary, students should have the opportunity to self select, or be selected, to participate in a real world project based on their aptitudes and preferences. And students should be told up-front about the challenging features of a project. 


\section{Student as Coachee}

The role of the student in project learning is inextricably linked to the role of the teacher. Therefore any discussion of student roles must also address teacher roles. A teacher can perform the roles of expert, formal authority, personal model, facilitator, delegator, and more in the classroom (Grasha, 1994). The role of teacher as coach is associated with real world projects (Bolton, 1999).

A coach inspires, models, guides, trains, challenges, sponsors, and helps the "coachee" succeed by increasing motivation, enhancing abilities, and providing support (Longenecker \& Pinkel, 1997). O’Neil \& Hopkins (2002) define the teacher as coach role as having three elements: building relationships; increasing students' self-discovery and self-knowledge through co-inquiry; and seeking to combine theory with practice via a pragmatic orientation (p. 404).

What is the role of the student as coachee? Based on the O'Neil and Hopkins model, the student as coachee role includes: willingness to be part of a relationship of dialogue with the teacher; willingness to pursue the project as a "co-inquirer" with the teacher; and willingness to apply learning to the real world project.

First, the student must seek instruction and advice on the project from the teacher. It is the students' responsibility to engage the teacher when the team needs help. The dialogue approach to teaching emphasizes the "interactive, cooperative, and relational aspects of teaching and learning" (Tiberius, 1986). The dialogue between the teacher and students must be ongoing, especially since the design of the project may "emerge" over time, and the teacher only has periodic input. This is the basis for the "just-in-time" approach to teaching, where the teacher provides guidance at strategic intervals during the semester (Bolton, 1999).

Second, the students and teacher approach the project as "co-inquirers." Co-inquiry was originally conceived as a process by which a researcher and participant jointly reveal knowledge. Teacher and students are co-inquirers because each project is unique and has no right or wrong answers. Teacher and students may contribute ideas, and draw different conclusions from the project experience and learn different things. The "co-inquiry" process requires that students shed their traditional roles of receivers of knowledge, and that teachers avoid being transmitters of knowledge.

Finally, students must take responsibility for applying course content to the real world project. Students are most qualified to apply theories to their project because they are the "experts" on their team's client and needs. The process of bridging the gap between academic theory and real world application not only helps students to understand the theory, but gives students a competence to apply theories to future problems. The teacher as coach facilitates this process. In summary, a student as coachee is ready to seek instruction and advice from the instructor as a "coinquirer," and to apply academic course content to the real world project objectives.

\section{Student as Contributor}

What about the overhead associated with managing a class of team projects? Depending on the course format, there may be a lot to do. A teacher may face the problem of being consumed with administering the course, at the expense of teaching.

One option is to delegate overhead tasks to students. Classrooms are full of talented students. It stands to reason that a teacher who can harness the talent and energies of students to contribute to a course will create a better learning experience. It is a waste to not involve the talents of students in the learning process.

Cahn (2000) discussed "co-production" in the context of getting social services recipients to participate in the process by which they are served. Co-production relies on a non-monetary market in which each person's "time in service" is the currency. It begins with the belief that each person can provide a valuable service to someone else. In Cahn's education example, grade school students earned credits toward a recycled computer by tutoring lower-grade 
students, a process that improved the performance in school of tutor and tutee (p. 101). Marketers have found that consumers can improve a product or service by participating in its production or delivery (Song \& Adams, 1993).

The author has involved student teams in the "production" of learning by assigning a "contribution" portion of the course grade (about 6\% of the total). Although technically an assignment, the term "contribution" better described its purpose, which was to add value to everyone's learning experience (Johnston, 1996, p. 6-7). Student teams coordinated the logistics of a public event (e.g. trade show or open house); created and posted flyers; wrote and sent press releases and other publicity efforts; compiled project abstracts into a program; coordinated presentations, etc. Students also helped their peers to learn the course subject matter, by publishing study guides and presenting review sessions. Essentially each team served the entire class as a second client.

Students can use the Internet to "add value" for their classmates. Students in an e-commerce course marketing course used free, web-based "blog" software to contribute to an online study guide, available to all students (Johnston, 2002). Publishing work online enabled students to make contributions to the class, promoted peer learning, and encouraged quality work. Teachers have shied away from reaping these benefits because of the effort needed to create and maintain class web pages. The blog method requires simple software, minimal training, and delegates the task of posting information to the students. Also, a course management system (e.g. BlackBoard) makes it relatively simple for a student to post documents and PowerPoint files to an online discussion board and make them available to all students.

In summary, students can contribute to the course by performing "overhead" tasks, which by themselves can be valuable real world experiences. Students can help their peers learn course material. Students are motivated because the product of their efforts has real value to their peers, and will be published for everyone to see. By engaging students as contributors to the course, the teacher can harness student talents to improve the learning experience. The teacher can then focus on teaching and not on administrative tasks.

\section{Student as Team Member}

Students may learn teamwork as an incidental by-product of the project process, or teamwork may be the academic course subject. Many of the "team learning" concepts discussed in this chapter were pioneered in organizational behavior courses in which teamwork was an important academic topic (Michaelsen et al, 2004).

The student and teacher share responsibility for developing effective teams. Researchers have criticized the notion that cohesive teams will form naturally (Deeter-Schmelz, Kennedy \& Ramsey, 2002) or that skills will necessarily transfer between student projects and real work teams (Ettington \& Camp, 2002). Holmer (2001) suggested that students may learn "skilled incompetence" by participating in poorly designed team projects.

Some researchers have called for teachers to re-examine their use of teams in courses because of serious pedagogical problems (McCorkle, et al, 1999). The methods for forming teams and teaching teamwork are beyond the scope of this chapter (see Peterson, 2004; Williams, Beard \& Rymer, 1991; Siciliano, 2001; Wood, 2003; Stinson \& Milter, 1996; Wilkerson \& Gifselaer, 1996).

A student should be willing to participate in the team, build up the team, and learn teamwork. "Free-riding" is one of the biggest problems in project learning (Joyce, 1999; Ashraf, 2004). The responsibility of each student is to subordinate his or her preferences to the objectives of the team, and to work for the good of the team. There is no substitute for a team-player attitude, because mechanisms to control free-riding are imperfect and the controls themselves can be distracting.

\section{Student as Academic Scholar}

The student "scholar" role means that a student must learn the academic course content, and not just participate in a project for its own sake. Projects may contain unique objectives; hence students assigned to different 
projects may have very different learning experiences. The lack of "standardization" of learning experiences is a potential drawback of projects.

A student may have a unique experience by pursuing a narrow set of specialized project objectives, by design. How can the teacher assure that students are mastering the broader course content? One option is to combine the full range of academic content of a course with an additional project. The result can be a course workload that is far beyond the norm, which can cause resentment among students and burnout of the teacher. Another option is to accept that students will learn a narrow, possible atypical set of skills and knowledge that are associated with their team project.

A third option is to make learning the subject matter part of the student's role. Society is becoming more doit-yourself (DIY) oriented. The fact that people often prefer to make their own travel plans and place their own stock trades has led to the near extinction of face-to-face service in these retail industries. Computer networks in general have contributed to the DIY trend in higher education. Students often prefer self-directed tasks over mediated tasks at school, such as paying fees, planning their course schedules, and registering for classes. Course management software programs in particular (BlackBoard, WebCT, etc.) have encouraged self-directed learning in higher education. A teacher can set up a schedule of online assessments to encourage students to read and master broad subject matter, and hold them accountable for progress.

The author found that $90 \%$ of students preferred online to pen-and-paper homework assessments (Johnston, 2004). The students had experienced both online and pen-and-paper methods (in a previous course with the same teacher). Also, a large majority (86\%) believed that their homework performance would be better with the online method than with the pen-and-paper method. (Homework performance was defined as the percentage of assignments that were submitted on time and of acceptable quality.) The actual homework performance of students who used the online method was substantially similar to that of students who used the pen-and-paper method.

Students' strong preference for online over the pen-and-paper homework suggests a "hybrid" online/project learning course. Students like to have control over the homework process. They like the capability of completing their homework at their convenience, and to work ahead of the class schedule. They like the ability to get immediate feedback, see their grades in the grade book, and return to view the assessment later. The online method eliminates some of the potential problems of the pen-and-paper method for students: failure to obtain the paper assessment, failing to submit responses, failure to receive feedback on the responses, and the teacher's failure to record the grade.

The online homework method has benefits and drawbacks for the teacher as well. The teacher is freed from copying, distributing, collecting, scoring and recording grades, and returning homework documents. The purposes of homework - to keep students engaged with the material and on track with the course-are preserved. The online method automates the repetitive tasks that add little value to the teaching process. Moving these repetitive tasks outside of the class time period enables students and teacher to do more interesting things in the classroom, such as work on a project. Drawbacks are the teacher's effort required to put homework assessments online, and to troubleshoot student and course management software problems.

Another option is make learning the course content part of the team's role and keep the do-it-yourself tasks offline. Michaelsen \& Black (1994) presented a process for combining individual and team input into assessments. The author has used this method to encourage students to read and master broad subject matter, while using only a small percentage of class time. The author assigned a schedule of textbook chapter readings. On a chapter's due date, each student was asked to complete a brief pencil-and-paper quiz (10 multiple choice questions). After submitting his or her responses, each student met with his or her teammates and completed the quiz again, and submitted one team response.

Students usually resolved any uncertainties about the questions within the group, and occasionally "appealed" questions to the teacher. Both scores counted toward a student's grade, and the group's score was usually equal to or higher than the individual scores. The individual score made a student accountable for his or her preparation. The team meeting showed the degree to which individual members had prepared, and the importance of 
everyone's input on important decisions. A student who failed to prepare risked receiving a low individual quiz score and a low peer evaluation.

This method gave students an opportunity to work together successfully as a team early on in the course. Another benefit is that it encouraged students to make progress on learning the subject matter, while spending the majority of their time on the team project. As with the online method, the freewheeling nature of giving quizzes to teams can raise questions about the authenticity of the work. For both methods the author gave exams in a relatively secure classroom setting so that students could demonstrate their mastery of the course content.

Both the online and team-learning methods encouraged students to make progress on learning the subject matter, without taking much class time, and thereby freed up time to work on the team project. These approaches to teaching course content are consistent with the project learning philosophy of giving students more responsibility for, and control over, their learning.

In summary, a student as ready learner has considered his or her aptitudes and preferences, and chosen to fully accept the challenges of a real world project, and the responsibility for its success. A student as coachee is ready to seek instruction and advice from the instructor as a "co-inquirer," and to apply academic course content to the real world project objectives. A student as contributor is willing to contribute his or her talents to add value to the course improve the learning experience of the class as a whole. A student as team member is willing to participate in the team, build up the team, and learn teamwork. A student as academic scholar is willing to take responsibility for learning the course material, and to work alone and with his or her team mates to master it.

\section{STUDENT RESPONSIBILITIES IN THE PROJECT PROCESS}

This paper has presented five general roles for students that are appropriate for team projects. What are appropriate responsibilities of students and teacher in the project process? A teacher who clearly delineates a student's responsibilities in the project process may minimize the student's "ambiguity aversion." Another goal is for the teacher to set the expectation that the student is responsible to deal with the ambiguity. Clear responsibilities prepare a student to expect a more active role than is typical in non-project courses. Bacon, Stewart \& Silver (1999) found that the clarity of instructions to the team positively affected student experiences. Well-defined responsibilities can also help the teacher maintain his or her workload and course overhead at a manageable level. Please see Table 2 for the proportion of teacher, student, and client responsibility for each step in the project process.

Table 2: Teacher, Student, and Client responsibilities

\begin{tabular}{|c|c|c|c|c|c|}
\hline Set learning goals & \multicolumn{5}{|c|}{$100 \%$ Teacher } \\
\hline Engage client & \multicolumn{3}{|c|}{$80 \%$ Student } & $10 \%$ & $10 \%$ \\
\hline Set objectives & \multirow{2}{*}{\multicolumn{2}{|c|}{$\begin{array}{c}10 \% \\
\text { Teacher }\end{array}$}} & \multicolumn{3}{|c|}{$30 \%$ Client } \\
\hline Implementation & & & $\begin{array}{c}10 \% \\
\text { Teacher }\end{array}$ & $20 \%$ & \\
\hline Report results & \multicolumn{5}{|c|}{$100 \%$ Student } \\
\hline Assess performance & $20 \%$ Student & $70 \%$ & her & & $\begin{array}{c}10 \% \\
\text { Client }\end{array}$ \\
\hline
\end{tabular}

This project model is not unique, but is typical, and the responsibility percentages for each role were derived mainly from the author's experience. The project steps are (1) set learning goals, (2) engage a client, (3) set project objectives, (4) implementation, (5) report results, and (6) assess performance. What follows is a discussion of each 
step, with suggestions for the proportion of responsibility that should be given to the student, teacher, and client. The bias of this paper is to assign as much responsibility for the project as possible to the students.

\section{Set Learning Goals}

A teacher typically has $100 \%$ of the responsibility to set the learning goals of a course of study. The project is generally one part of a course, which may in turn be part of a larger plan of study (e.g. a degree and major field). Learning goals are different from the project objectives, which will be discussed later. Learning goals are "metagoals" which refer to the reasons for doing a project rather than the outcomes of a project.

A teacher sets project learning goals to link a real world problem or task with course subject matter topics. For example, the author defined learning goals for a marketing management course with a team project as: (1) identify and describe the marketing strategy of an organization; (2) create and implement a promotion plan for an organization; (3) contribute to a team to solve problems in the pursuit of marketing opportunities; and (4) use proper communication techniques to talk to a business person (Johnston, 1996). With the exception of relatively rare selfdirected courses, the student's role in setting learning goals for a course of study is limited.

\section{Engage a Project Client}

Students may take $80 \%$ of the responsibility of engaging a client, which includes identifying a prospect, approaching and setting an appointment, interviewing and persuading a prospect, and obtaining a client engagement letter. By meeting with students and making the commitments embodied in the client letter, the client has perhaps $10 \%$ of the responsibility during the engagement process. The teacher also has about $10 \%$ of the responsibility, which involves reviewing the engagement letter and verifying that the client fits the recruiting guidelines.

In some cases the teacher should obtain the client. If the teacher has very specific project tasks in mind, then he or she could recruit a client who needs these tasks performed. If the teacher knows of a willing client who could provide multiple projects for a few student teams, then it would be simpler to use the teacher's contact than for students to recruit clients. Generally, students can obtain their own clients. The process of recruiting a client is itself a valuable real world experience, because students get to approach and persuade a prospective client to join the project.

The teacher can guide the students by providing general client selection guidelines and a deadline. For example, the author defined client selection criteria for a team project as follows: (1) Client location is convenient for team-client meetings; (2) Client product or service has appeal to the campus community, and the client would benefit by being promoted to the community; (3) Client product or service has some "sizzle" appeal to generate excitement among students and prospective customers, and community members would benefit by seeing the promotion; (4) Client contact person is an adult (not a student), and serves a managerial role and can make decisions to spend money and take action; (5) Client contact person is interested in and willing to spend time with students; and (6) Client product or service fits with the theme of the trade show (Johnston, 1996, p. 51).

The author has not allowed student teams to recruit other students or student organizations as clients. This is to encourage students to get out of their comfort zone and into the real world, and to prevent "fake" projects. This may not be a concern when the teacher is supervising a few teams.

The campus community can be a source of clients, again depending on the course topic. For example, the author has supervised projects with university departments. Most organizations, including profit, not-for-profit, and government, have "customers." They need to understand and communicate with their customers, and hence have market research and promotion needs. These needs can be translated into objectives for marketing projects. Most organizations have employees, and hence have personnel management issues. All organizations have a mission and a strategy, whether they realize it or not, and are potential clients for a strategic management project. 
A successful recruiting process should yield a "client engagement letter" on the client's letterhead. Students should direct the client to verify in the letter that he or she understands the client role and has realistic expectations for the project. It is good practice for the teacher to reply to the engagement letter on university letterhead. A letter adds a touch of formality to the assessment, provides an opportunity to state the commitments of the students and teacher to the project, and provides contact information to the client.

\section{Determine Project Objectives}

Students can have about $60 \%$ of the responsibility for setting project objectives and tasks. The client has about $30 \%$ of the responsibility, to work with students to ensure that project objectives meet the needs of the organization. The teacher has about $10 \%$ of the responsibility for determining each project's objectives.

It has been said that "defining the problem is half of the solution." A successful real world project starts with objectives that are important to a client and achievable by students within an academic term. The teacher can simplify the process by clearly specifying the criteria for objectives, offering a menu from which students and client can choose objectives, or providing examples of objectives. When a teacher intervenes to modify proposed objectives it is usually to make them more focused and quantifiable. Students often submit objectives that are vague, far-reaching, and not practical to pursue.

The teacher can provide generic objectives that reinforce the course learning goals. The students and client can then decide how to apply the objectives to the client's needs, and how to implement an "action plan" and measure the results. For example, the author has defined a generic objective for a market research class as "perform a market survey." The students and clients then decided on specific objectives such as the market of interest (current customers, non-customers, target segments, etc.) and the information desired (customer satisfaction, product usage, customer perceptions about competitors, etc.). This approach yielded projects with objectives and tasks that were unique, yet aligned with the academic topics of a market research course.

The author defined a generic objective for a marketing principles class as "promote your client at a trade show." Tasks included interviewing the client, conducting a survey, creating a flyer, and developing and implementing a promotion plan. The role of students was to determine the promotion need of the client, craft the message and materials, and stage a "booth" at a trade show. Although students started with "generic" objectives and tasks, they produced unique promotional efforts for their client and thereby had a unique learning experience.

In some situations, students can be a source of their own projects. Students in a marketing research course applied the principles of marketing research to the course, to identify what student "customers" wanted from the course (Bridges, 1999). Students in an organizational behavior course applied course concepts to solve problems that students had within their work, school, or home groups (Miller, 2004). Entrepreneurship students raised funds and recruited members for student organizations (Daly, 2001).

For example, the author has taught students to sell items (of their choice) on eBay. By listing an auction a student can experience first-hand the issues that face all e-commerce merchants, such as choosing products, crafting offers and web pages, and receiving payments and fulfilling orders. Working with the eBay web site gives students two perspectives on the e-commerce customer interface - the perspective of a seller creating an auction for a good, and the perspective of a seller as a buyer of services from eBay (Johnston, 2003).

\section{Implementation}

Students can be responsible for $70 \%$ of the implementation, clients $20 \%$, and the teacher can have $10 \%$ of the responsibility. The students' role is to satisfy the client, so most of their interaction should be with the client and within the team. Depending on the scope of the project, the teacher may have infrequent or no direct contact with the clients in the course of the project. 
What is implementation? Implementation is the process of pursing the project objectives and tasks, and the outcomes of that pursuit (i.e. carrying out the action plan). Students generally have to meet as a team several times, and meet with the client a few times as well. Setting up meetings with a busy client and equally busy students is a challenge in itself and a useful real world experience. Teachers have found that allocating class time for some team meetings helps to mitigate the scheduling problem and improve the team experience (Papamarcos, 2002; McKendall, 2000).

Although students are primarily responsible for implementation, the teacher has an important role to keep students on task. The teacher's role in general is to set interim deadlines, review drafts of work, and hold students accountable for progress. With any luck the student teams will be "self-managed" and the teacher will need to intervene only when asked for advice or to provide occasional discipline and motivation to stalled teams. The teacher also is responsible for teaching team management issues.

This brings up a related question: Should the teacher allow the student team to fail? If "success" is defined as meeting the project goals, then yes, the team should be allowed to fail. Like an athlete, a student must be willing to experiment, alter behaviors, and strive for improved performance (Bolton, 1999). Students who do not pursue the project, do not exert any effort, and are not open to coaching (discussed earlier in this paper) should see that the consequences of these behaviors are failure. For a teacher to intervene with a team of slackers and force them to perform or "rescue" the team would be doing the students a disservice. On the other hand, if "success" is defined as learning something, then the teacher should not allow the team to fail, because students can reflect on an otherwise failed project and successfully learn what to do differently in the future.

\section{Report On Results}

Students have $100 \%$ of the responsibility to report on the results of their project. Assuming that students began the project with clear, measurable objectives, then finishing with a report on the team's accomplishments is a fairly straightforward task. Often students produce a written report on the project. A written report format is universally understood and easy to handle for everyone involved.

Students can get focused on the report itself to the detriment of its contents, however. Plus, even real world written reports sometimes fail to find an audience. An option is to downplay the report and emphasize other "deliverables" instead, such as oral presentations, posters, models, etc. Students who display or present their work in a class or public forum can get instant feedback and recognition.

Using oral presentations, poster sessions, or trade show booths to report results also creates a hard deadline for students. Students cannot slip a presentation under the teacher's office door like a written report. Students can also present results to a wider audience, including client representatives, expert judges, and other students. Plus, students can learn a lot by viewing the work of their peers. Teachers have found the trade show format useful for integrating classes in different disciplines (Bobbitt et al, 2000) and for teaching large classes (Taylor, 1998).

\section{Assess Performance}

The teacher is responsible for $70 \%$ of performance assessment, the student contributes $20 \%$, and the client $10 \%$. The teacher has most of the responsibility for assessing student performance on a project. The teacher must assess the quality of work as well as its fit with project objectives, in the context of student teams serving unique clients. Ultimately a teacher assigns an individual course grade for each student. Should a student receive an individual grade for his or her contribution to the team's performance? If the team members receive a common grade, how much should the grade count toward a student's individual course grade? Should students grade each other?

One option is to make the team project grade a small proportion of the individual course grade, but this can cause a problem when the team project work is a large proportion of the course work. McKendall (2000) said 
students should receive a team grade for the team output of a project, and to assign individual grades is to defeat the concept of teamwork. Team work should have team rewards (Kerr, 1975).

A student may have some responsibility for evaluating his or her own performance. Student self-evaluation, peer evaluation, and client evaluation can provide valuable feedback to the student. Self-evaluation can prompt students to reflect on their learning, and reflection is an important element of active learning (Ayas \& Zenuik, 2001).

Students can experience the real world task of evaluating others by giving feedback to their peers. The prospect of receiving peer feedback can be a source of learning as well as an incentive to contribute to the team and a disincentive to free-riding behavior. Chen \& Lou (2004) found that students saw peer evaluations as valuable if the evaluations were used to determine grades. Peer evaluations can be used to reduce intra-group conflict and remedy an uneven distribution of workload. Paswan \& Gollakota (2004) developed a multi-item scale to rate peer performance on dependability, task and maintenance orientation, domineering behavior, free-riding behavior, and individual competence.

The results from research on student preferences regarding peer evaluations are mixed. Chapman, Van Auken \& Stuart (2001) found that "students were more likely to have positive attitudes about group work if they had instructors who . . . used methods to evaluate individual performance within the group (e.g. peer evaluations)." Bacon, Stewart \& Silver (1999) found that the use of peer evaluations was negatively associated with student ratings of "good" team experiences.

Finally, the client has a role in evaluating how well the students served his or her needs in completing the project. Client feedback can be the "acid test" of the project's real world contribution. While this may seem like a lot of evaluations, the process is consistent with a real world "360 degree feedback" system (Lepsinger \& Lucia, 1997).

\section{CONCLUSION}

Real world projects are an active learning approach in which teams of students pursue real world objectives as part of an academic course of study. This paper presented special "co-production" roles for students, to assure that students learn from participating in the project: (1) ready learner, (2) coachee, (3) contributor, (4) team member, and (5) academic scholar.

This paper presented a unique approach of focusing on student responsibilities in real world projects. Students can share responsibility for important managerial tasks: engage a client (80\% student responsibility), set project objectives (60\%), take action (70\%), report on results (100\%), and assess performance and be assessed (20\%). The teacher has most of the balance of the responsibilities, with the client playing a supporting role.

Teaching with real world projects has benefits and challenges. The benefits are great, and a teacher can minimize the challenges and costs by defining clear roles and responsibilities in co-producing the learning experience. A team project with well-defined roles and responsibilities can be good learning experience for students, teacher, and client. Future research can test more formally the hypothesis that student roles in projects discussed in this paper enhance learning and student satisfaction with learning. A second hypothesis is that clear responsibilities contribute to student learning, and to the satisfaction of students, teacher, and clients.

\section{REFERENCES}

1. Ashraf, Mohammad (2004). A Critical Look at the Use of Group Projects as a Pedagogical tool. Journal of Education for Business, 79(4), 213-216.

2. Ayas, Karen \& Nick Zeniuk (2001). Project-based Learning: Building Communities of Reflective Practitioners. Management Learning, 32, 61-76.

3. Bacon, Donald R., Kim A.Stewart, \& William S. Silver (1999). Lessons From the Best and Worst Student Team Experiences: How a Teacher Can Make the Difference. Journal of Management Education, 23, 467488. 
4. Bobbitt, L. Michelle, Scott A. Inks, Katie J. Kemp, \& Donna T. Mayo (2000). Integrating Marketing Courses to Enhance Team-Based Experiential Learning. Journal of Marketing Education, 22(April), 15-24.

5. Bolton, Michele Kremen (1999). The Role of Coaching in Student Teams: A "Just-in-Time" Approach to Learning. Journal of Management Education, 23, 233-250.

6. Bridges, Eileen (1999). Experiential Learning and Customer Needs in the Undergraduate Marketing Research Course. Journal of Marketing Education, 21, 51-59.

7. Cahn, Edgar S. (2000). No More Throw-Away People: The Co-production Imperative. Washington DC: Essential Books.

8. Chapman, Kenneth J. \& Stuart Van Auken (2001). Creating Positive Group Project Experiences: An Examination of the Role of the Instructor on Students' Perceptions of Group Projects. Journal of Marketing Education, 23, 117-127.

9. Chen, Yining \& Hao Lou (2004). Students' Perceptions of Peer Evaluation: An Expectancy Perspective. Journal of Education for Business, 79(5), 275-280.

10. Crustinger, Christy A., Sanjukta Pookulangara, Gina Tran, \& Kim Duncan (2004). Collaborative Service Learning: A Winning Proposition for Industry and Education. Journal of Family and Consumer Sciences, 96(3), 47-52.

11. Daly, Shawn (2001). Student-operated Internet businesses: True experiential learning in entrepreneurship and retail management. Journal of Marketing Education, 23 (December), 204-215.

12. Deeter-Schmelz, Dawn R., Karen Norman Kennedy, \& Rosemary P. Ramsey (2002). Enriching Our Understanding of Student Team Effectiveness. Journal of Marketing Education, 24, 114-124.

13. Ettington, Deborah R. \& Richaurd R. Camp (2002). Facilitating Transfer of Skills Between Group Projects and Work Teams. Journal of Management Education, 26, 356-379.

14. Grasha, A. F. (1994). A matter of style: The teacher as expert, formal authority, personal model, facilitator, and delegator. College Teaching, 42, 142-149.

15. Holmer, Leanna L. (2001). Will We Teach Leadership or Skilled Incompetence? The Challenge of Student Project Teams. Journal of Management Education, 25, 590-605.

16. Johnston, Timothy C. (1996). Marketing Management: The Hands-on/Team Learning Approach. Knoxville, TN: Self published.

17. Johnston, Timothy C. (2002). Teaching with a Weblog: How to Post Student Work Online. Proceedings of the Academy of Educational Leadership, pp. 33-38.

18. Johnston, Timothy C. (2003). Using eBay to teach E-commerce. Proceedings of the American Society of Business and Behavioral Sciences, 10:1, 700-706.

19. Johnston, Timothy C. (2004). Online Homework Assessments: Benefits and Drawbacks for Students. Academy of Educational Leadership Journal, 8:3, 29-41.

20. Joyce, W.B. (1999). On the free-rider problem in cooperative learning. Journal of Education for Business, $75,271-74$.

21. Kerr, S. (1975). On the folly of rewarding A while hoping for B. Academy of Management Journal, 18, 769-783.

22. Lepsinger, Richard \& Anntoinette D. Lucia (1997). The Art and Science of 360 Degree Feedback. San Francisco: Pfeiffer.

23. Longenecker, C. O. and G. Pinkel (1997). Coaching to win at work. Manage, 48(2), 19-21.

24. McCorkle, Denny E., James Reardon, Joe F. Alexander, Nathan D. Kling, Robert C. Harris \& R. Vishwanathan Iyer (1999). Undergraduate Marketing Students, Group Projects, and Teamwork: The Good, the Bad, and the Ugly? Journal of Marketing Education, 21(2), 106-117.

25. McKendall, Marie (2000). Teaching groups to become teams. Journal of Education in Business, 75, 277282.

26. Michaelsen, Larry K. \& Robert H. Black (1994). Building Learning Teams: The Key to Harnessing the Power of Small Groups in Higher Education. Collaborative Learning: A Sourcebook for Higher Education, Vol. 2. State College, PA: National Center for Teaching, Learning \& Assessment, accessed online October 27, 2004 at ftp://www.ntlf.com/ntlf/teamlearn.doc.

27. Michaelsen, Larry K., Arletta Bauman Knight \& L. Dee Fink, eds. (2004). Team-Based Learning: A Transformative Use of Small Groups in College Teaching. Sterling, VA: Stylus Publishing. 
28. Miller, Janice S. (2004). Problem-Based Learning in Organizational Behavior Class: Solving Students' Real Problems. Journal of Management Education, 28, 578-590.

29. O'Neil, Deborah A. \& Margaret M. Hopkins (2002). The Teacher as Coach Approach: Pedagogical Choices for Management Educators. Journal of Management Education, 26, 402-414.

30. Papamarcos, Steven D. (2002). The next wave" in service learning: integrative, team-based engagements with structural objectives. Review of Business, 23(2), 31-39.

31. Paswan, Audhesh K. \& Kamala Gollakota (2004). Dimensions of Peer Evaluation, Overall Satisfaction, and Overall Evaluation: An Investigation in a Group Task Environment. Journal of Education for Business, 79(4), 225-231.

32. Peterson, Tim O. (2004). So You're Thinking of Trying Problem Based Learning?: Three Critical Success Factors for Implementation. Journal of Management Education, 28, 630-647.

33. Siciliano, Julie I. (2001). How to Incorporate Cooperative Learning Principles in the Classroom: It's More Than Just Putting Students in Teams. Journal of Management Education, 25, 8-20.

34. Song, Jae H., and Carl R. Adams (1993). Differentiation through customer involvement in production or delivery. Journal of Consumer Marketing, 10(2), 4-12.

35. Stinson, J. E. \& R. G. Milter (1996). Problem-based learning in business education: Curriculum design and implementation issues. In L. Wilkerson \& W. H. Gijselaers (Eds.), Bringing problem-based learning to higher education: Theory and practice (pp. 33-42). San Francisco: Jossey-Bass.

36. Taylor, Kimberly A. (1998). The Marketing Trade Show: A New Method for Incorporating Student Projects in to Large Classes. Journal of Marketing Education, 20(3), 250-257.

37. Tiberius, R. G. (1986). Metaphors underlying the improvement of teaching and learning. British Journal of Educational Technology, 17, 144-156.

38. Wilkerson, L. \& W. H. Gijselaers (Eds.). Bringing problem-based learning to higher education: Theory and practice. San Francisco: Jossey-Bass.

39. Williams, David L., John D. Beard, \& Jone Rymer (1991). Team projects: Achieving their full potential. Journal of Marketing Education, 11, 64-71.

40. Wood, Charles M. (2003). The Effects of Creating Psychological Ownership among Students in Group Projects. Journal of Marketing Education, 25, 240-249. 